\title{
Simulation Training in Neuroangiography-Validation and Effectiveness
}

\author{
Kornelia Kreiser $^{1}$ (D) - Lea Ströber ${ }^{1} \cdot$ Kim G. Gehling $^{1} \cdot$ Frederick Schneider $^{2} \cdot$ Stefan Kohlbecher $^{3}$. \\ Christian M. Schulz ${ }^{2}$. Claus Zimmer ${ }^{1}$. Jan S. Kirschke ${ }^{1}$
}

Received: 23 October 2019 / Accepted: 25 March 2020 / Published online: 17 April 2020

(C) The Author(s) 2020

\begin{abstract}
Purpose Simulators are increasingly used in the training of endovascular procedures; however, for the use of the Mentice vascular interventional system trainer (VIST) simulator in neuroradiology, the validity of the method has not yet been proven. The study was carried out to test the construct validity of such a simulator by demonstrating differences between beginner and expert neurointerventionalists and to evaluate whether a training effect can be demonstrated in repeated cases for different levels of experience.

Methods In this study 4 experts and 6 beginners performed 10 diagnostic angiographies on the VIST simulator (Mentice $\mathrm{AB}$, Gothenburg, Sweden). Of the cases four were non-recurring, whereas three were repeated once and ten subjects performed all tasks. Additionally, another expert performed only five non-recurring cases. The simulator recorded total time, fluoroscopy time, amount of contrast medium and number of material changes. Furthermore, gaze direction and heart rate were recorded, and subjects completed a questionnaire on workload.

Results Beginners and experts showed significant differences in total duration time, fluoroscopy time and amount of contrast agent (all $p<0.05)$. Gaze direction, dwell time and heart rate were similar between both groups. Only beginners improved during training with respect to total duration time, fluoroscopy time and amount of contrast agent. If a case was previously known to them, the total duration and fluoroscopy time were significantly shortened $(p<0.001)$.

Conclusion This study demonstrated both the construct validity of a diagnostic neuroangiography simulator as well as a significant training effect for beginners. Therefore, in particular beginner neurointerventionalists should use such simulation tools more extensively in their initial training.
\end{abstract}

Keywords Neuroradiology $\cdot$ Training effect $\cdot$ Validity $\cdot$ Eye tracking $\cdot$ Work load

\section{All authors contributed to the study conception and design. Material preparation, data collection and analysis were performed by Lea Ströber, Kim Gehling, Frederick Schneider, Stefan Kohlbecher, Christian Schulz, Jan Kirschke und Kornelia Kreiser. The first draft of the manuscript was written by Kornelia Kreiser and all authors commented on previous versions of the manuscript. All authors read and approved the final manuscript.}

Kornelia Kreiser

kornelia.kreiser@tum.de

Lea Ströber

lea.stroeber@mnet-mail.de

Kim G. Gehling

kim@gehling.de

Frederick Schneider

frederick.schneider@tum.de

Stefan Kohlbecher

skohlbecher@eyeseetec.de

Christian M. Schulz

c.schulz@tum.de
Claus Zimmer

claus.zimmer@tum.de

Jan S. Kirschke

jan.kirschke@tum.de

1 Department of Diagnostic and Interventional Neuroradiology, Klinikum rechts der Isar, Technische Universität München, Ismaninger Str. 22, 81675 Munich, Germany

2 Department of Anesthesiology, Klinikum rechts der Isar, Technische Universität München, Munich, Germany

3 EyeSeeTec GmbH, Munich, Germany 


\begin{tabular}{ll}
\multicolumn{2}{l}{ Abbreviations } \\
bpm & Beats per minute \\
F & French \\
IQR & Interquartile range \\
NASA TLX & $\begin{array}{l}\text { National Aeronautics and Space Administra- } \\
\text { tion Task Load Index }\end{array}$ \\
RTLX & RAW TLX (unweighted task load index) \\
rtPA & Recombinant tissue plasminogen activator \\
SD & Standard deviation \\
STL & Stereolithography (file format) \\
VER & Vertebralis catheter
\end{tabular}

\section{Background/Introduction}

The number of endovascularly treated patients suffering from stroke or aneurysms has steadily increased over the last few years [1]. In 2015, five large randomized stroke trials established the superiority of mechanical thrombectomy in combination with intravenous recombinant tissue plasminogen activator (i.v. rt-PA) over i.v. rt-PA alone [2-6]. Since then, the number of treated patients has risen continuously. Moreover, the time window has been recently broadened $[7,8]$, which will further increase the number of patients eligible for interventional treatment. Although mechanical thrombectomy is performed in more and more patients at centers with great expertise, demand is increasing for an on-call service around the clock at multiple smaller centers. Hence, a sufficient number of interventional neuroradiologists must be trained at a high level. Using highfidelity simulators offers the possibility of structured training without endangering patients $[9,10]$. Although the first prototypes of simulators specifically for neuroradiological applications were developed many years ago [11, 12], they are not yet widely used in neuroradiology. After proof of face and content validity, based on expert opinion [13] the next crucial step to establish such a new approach includes the demonstration of its construct validity, i.e. beginners and advanced users can be distinguished via the parameters measured by the simulator. Only when this prerequisite is met should such a simulator be used for training interventionalists. Concerning interventional procedures, construct validity was previously shown for renal [14, 15] and cardiac procedures $[16,17]$ as well as for carotid stenting [18, 19]. After the validity or neuroangiographies of another make, the ANGIO Mentor Express (Simbionix, Cleveland, $\mathrm{OH}, \mathrm{USA}$ ) has already been proven [20], the present study aimed at establishing the construct validity of the Mentice VIST simulator; however, construct validity is not directly related to the effectiveness of a simulator. To be used as an effective training tool in practice, improvements in psychomotor skills should be measurable [21, 22]. Therefore, the second aim of the study was to quantify improvements of different quality measures of a diagnostic neuroangiography, resulting from repeated simulator training. Of interest was, in addition to an already confirmed training effect for beginners and intermediates [10, 20, 23, 24], whether this impact could also be demonstrated for experts.

\section{Material and Methods}

\section{Hardware}

All neuroangiographic simulations were performed with the vascular intervention system trainer VIST C from Mentice (Mentice AB, Gothenburg, Sweden), integrated in the VIST LAB. This is a stationary unit whose surface is designed in the form of a patient silhouette (Fig. 1). The VIST LAB consists of a control screen with a touch screen function for selecting scenarios and materials, plus three additional monitors. On two of them, the examiner can follow the live image on two planes and on the third monitor can scroll through the recorded series. A laptop and the simulator itself are positioned under the surface. The only visible detail of the simulator is an insertion sheath at the height of the manikin's groin, which serves as the access point to the simulator for all materials. Pushing, pulling, and rotating movements of the introduced wires and catheters are detected by three sensors, which can also generate resistance in the sense of force feedback. These movements are transferred into a virtual patient anatomy, consisting of arteries and bones, and displayed on the screens in real time. A foot switch with two pedals, a panel with several options for controlling the virtual $\mathrm{C}$-arms and other settings (shutter, zoom, etc.), and a tube with a syringe for the injection of air, simulating the injection of contrast medium, are also connected to the simulator.

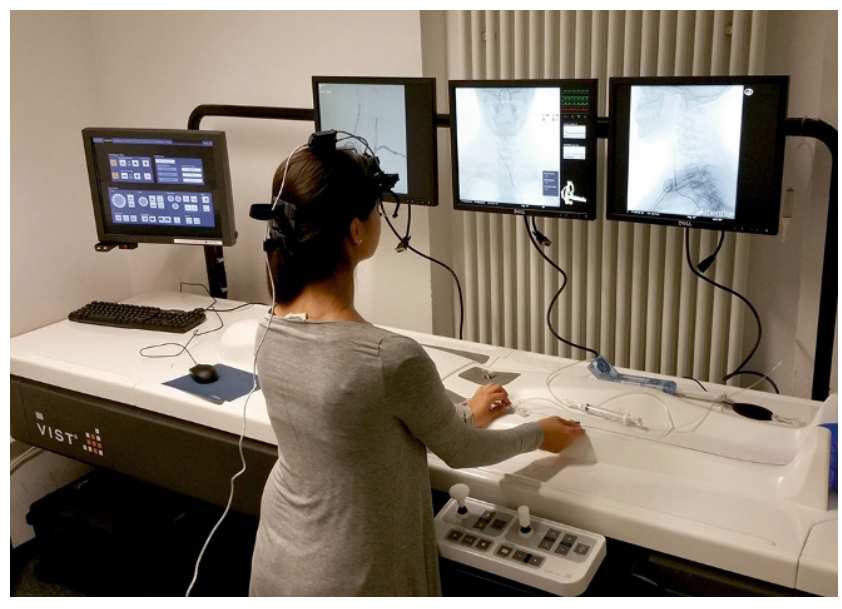

Fig. 1 Simulation set-up with VIST LAB and eye tracking camera (heart rate belt covered by shirt) 
Parameters stored by the device are total duration of the procedure, total fluoroscopy time, number of series, total series time, amount of contrast agent, and number of material changes.

\section{Endovascular Devices}

Real angiographic materials, such as a hydrophilic wire $\left(0.035^{\prime \prime}\right.$ Glidewire, Terumo, Somerset, NJ, USA) and a 5F vertebralis diagnostic catheter (VER, Cordis, Santa Clara, CA, USA) were used. All terminal curvatures had been cut off as required by the manufacturer of the simulator.

\section{Software}

The source data of magnetic resonance (MR) angiographies of real patients with different anatomical types of the aortic arch were segmented semi-automatically by using IntelliSpacePortal (Philips, Best, The Netherlands). The resulting 3D model was imported to the simulator as a Stereolithography (STL) file. The integrated Case-it software module (Mentice AB, Gothenburg, Sweden) connected the model of the aortic arch and the supra-aortic branches to a template of the descending aorta and the iliac arteries down to the superficial femoral artery.

\section{Accessories}

An eye-tracking camera (EyeSeeCam Sci, EyeSeeTec $\mathrm{GmbH}$, München, Germany) was used to record the viewing direction of the test persons. The pulse rate was recorded with a heart rate belt $\left(Z_{e}\right.$ ephyr ${ }^{\mathrm{TM}}$ BioModule ${ }^{\mathrm{TM}}$ Sensor, BioHarnessTM 3, Medtronic, Dublin, Ireland). Free MATLAB ${ }^{\circledR}$-based (MathWorks ${ }^{\circledR}$, Natick, MA, USA) ARTiiFACT software [25] was used to evaluate the mean heart rate. The whole set-up is presented in Fig. 1.

\section{Test Persons}

Participants were recruited from the radiology and the neuroradiology departments and divided into two groups. The expert group consisted of five physicians with advanced angiography experience from more than 100 cerebral angiographies each. One of them only completed the first five cases and then left the study. These data could only be included in the analysis of validity, but not in the evaluations of the training effect. The beginner group consisted of one medical student without any experience in angiography, three neuroradiological residents with little neuroangiographic experience $(<30)$ and two radiological residents with exclusively peripheral angiographic experience.
The local ethics committee approved the study (172/14), and each participant provided informed consent before participating.

\section{Study Design}

Each participant had to complete ten cases. Every case consisted of a complete cerebral angiography in one patient, i.e., the selective probing and visualization of the internal carotid artery, external carotid artery, and vertebral artery with their respective dependent branches on both sides. The ten cases were split in two study parts, where the first part included five unknown cases and the second part included two new cases and three repeated cases from the first part. In detail, the first case was repeated in case six, the fourth case in case nine and the fifth case in case ten. All cases were classified into five levels of difficulty by a neuroradiologist not participating in the study. The classification was based on the following criteria: level 1 was easy to perform with a VER catheter without using a roadmap due to standard anatomy; level 2 was also feasible with a VER catheter, but a roadmap was required; level 3 included an arterial norm variant, i.e., the left vertebral artery originated directly from the aortic arch. In level 4, a sidewinder catheter was required to solve the task. The highest level 5 required advanced catheter maneuvers and changes, plus precise knowledge of the vessel anatomy, variants, and possible pathologies. In each part of the study there was one case of each difficulty level. The participants were informed neither about the level nor about whether the presented case was a known or unknown one.

Before the first session, a technical introduction to the simulator was given, together with a shortened exercise session on a case that was not part of the study. The participant was equipped with a heart rate belt and a head-mounted camera. The individual simulation sessions were limited to a maximum of $2 \mathrm{~h}$ to avoid any possible fatigue effects. The operation of the simulator beyond the catheter guidance was the responsibility of a student. Each angiography was started with a hydrophilic guidewire $\left(35^{\circ}\right.$ curvature) and VER as standard, but the material could be changed at any time on request. At the end of each case, the investigators filled out a questionnaire to record the subjectively perceived workload (NASA-TLX, National Aeronautics and Space Administration Task Load Index, German translation, [26]) as rating with respect to mental demands, physical demands, temporal demands, satisfaction with performance, effort, and frustration. Each rating scale ranged from 0 to 20 . 
Table 1 Comparison of experts and beginners in a summary of all 10 simulations (one expert only performed simulations 1-5)

\begin{tabular}{|c|c|c|c|c|c|}
\hline \multirow[b]{3}{*}{ Simulation data: } & \multicolumn{5}{|c|}{ Simulations $1-10$} \\
\hline & \multicolumn{2}{|c|}{ Experts $(n=5)$} & \multicolumn{2}{|c|}{ Beginners $(n=6)$} & \multirow{2}{*}{$\begin{array}{l}p \text {-value } \\
-\end{array}$} \\
\hline & Mean & $\pm S D$ & Mean & $\pm S D$ & \\
\hline Total duration (min) & 19.65 & 7.73 & 31.96 & 15.07 & $p \leq \mathbf{0 . 0 0 1}$ \\
\hline Fluoroscopy time (min) & 11.91 & 4.59 & 18.78 & 7.72 & $p \leq \mathbf{0 . 0 0 1}$ \\
\hline Total time of series (min) & 1.90 & 0.80 & 1.75 & 0.79 & $p=0.269$ \\
\hline \multirow[t]{2}{*}{ Contrast agent (ml) } & 52.04 & 21.31 & 67.20 & 30.82 & $p=0.013$ \\
\hline & Median & $I Q R$ & Median & $I Q R$ & - \\
\hline Number of series & 16 & 10 & 16.5 & 9 & $p=0.976$ \\
\hline Number of material changes & 1 & 1 & 2 & 2 & $p=0.056$ \\
\hline NASA-TLX (range 1-20): & Median & $I Q R$ & Median & $I Q R$ & - \\
\hline Mental demand & 9.5 & 8 & 10.5 & 7 & $p=0.795$ \\
\hline Physical demand & 4.5 & 4 & 5 & 4 & $p=0.780$ \\
\hline Temporal demand & 7.5 & 7 & 6 & 6 & $p=0.324$ \\
\hline Satisfaction with performance & 17 & 4 & 15 & 6 & $p=0.008$ \\
\hline Effort & 11 & 7 & 15 & 5 & $p \leq \mathbf{0 . 0 0 1}$ \\
\hline Frustration & 6 & 4 & 5 & 5 & $p=0.095$ \\
\hline Physiological data: & Mean & $\pm S D$ & Mean & $\pm S D$ & - \\
\hline Heart rate (beats per minute/bpm) & 79.00 & 8.92 & 81.47 & 13.86 & $p=0.669$ \\
\hline Viewing direction $(\%)^{\mathrm{a}}$ & 29.38 & 14.40 & 30.08 & 14.60 & $p=0.502$ \\
\hline
\end{tabular}

Median and IQR for number of series, number of material changes and results of NASA-TLX, $p$-values of mediantest $<0.05$ are in bold type. Mean for total duration, fluoroscopy time, total time of series and amount of contrast agent, heart rate and gaze direction, $p$-values of Mann Whitney U-test $<0.05$ are in bold type

aPercentage of deviation of more than $30^{\circ}$ from the horizontal view downwards.

\section{Statistics}

Statistical analysis was performed by descriptive and exploratory statistics. Ordinal data (number of series, number of material changes, results of NASA-TLX) and metric data (total duration, total fluoroscopy time, total series time, amount of contrast agent, mean heart rate and percentage of gaze direction lower than $30^{\circ}$ ) were compared by using a median test or a Mann-Whitney U-test, respectively. Ordinal data are presented in median (interquartile range, IQR), metric data are presented as mean $( \pm$ standard deviation, $\mathrm{SD})$ if not stated differently. A $p$-value $<0.05$ was considered as statistically significant. All analyses were performed using IBM SPSS Statistics, Version 23.0 (IBM, Armonk, NY, USA).

\section{Results}

\section{Proof of Validation}

Comparative results of the experts and beginners of all 10 cases are listed in Table 1. Total duration time, total fluoroscopy time and amount of contrast agent differed significantly. With respect to the subjective task requirements, significant differences were observed in the assessment of satisfaction and effort. Beginners were more dissatisfied and had to make greater efforts than the experts. Nevertheless, heart rate and viewing direction did not differ between experts and beginners in the cases.

\section{Proof of Training Effectiveness}

In a comparison of the first five cases with the last five cases participants improved significantly in terms of total duration, fluoroscopy time and perceived effort (total duration $31.94 \mathrm{~min}$ (SD $16.41 \mathrm{~min}$ ) to 21.15 (SD $7.18 \mathrm{~min}$ ), $p<0.001$; fluoroscopy time $18.15 \mathrm{~min}$ (SD $8.55 \mathrm{~min}$ ) to $13.42 \mathrm{~min}$ (SD $4.87 \mathrm{~min}$ ), $p=0.003$; effort [median] 15 (IQR 7) to 13 (IQR 7), $p=0.031$ ); however, when results are separated for experts and beginners (Table 2), then this effect remained significant only in beginners. Fig. 2 visualizes the decrease of fluoroscopy time during the sequence of the training, although the degree of difficulty increased from 1 to 5 and 6 to 10 respectively. In addition, the beginners became more satisfied with their performance during the course of training. Similar differences were found when comparing unknown cases with known cases, where total duration time and fluoroscopy time differed significantly and participants were more satisfied with their performance (total duration $35.91 \mathrm{~min}$ (SD $16.03 \mathrm{~min}$ ) to $22.73 \mathrm{~min}$ (SD $6.37 \mathrm{~min}$ ), $p<0.001$; fluoroscopy time $20.66 \mathrm{~min}$ (SD $7.90 \mathrm{~min}$ ) to $14.39 \mathrm{~min}$ ( $\mathrm{SD} 5.19 \mathrm{~min}$ ), $p=0.003$; satisfac- 
Table 2 Comparison of experts and beginners of simulations 1-5 and 6-10 separately

\begin{tabular}{|c|c|c|c|c|c|c|c|c|c|c|}
\hline \multirow[b]{3}{*}{ Simulation data: } & \multicolumn{5}{|l|}{ Experts } & \multicolumn{5}{|c|}{ Beginners } \\
\hline & \multicolumn{2}{|c|}{$\begin{array}{l}\text { Simulation }(n=5) \\
1-5\end{array}$} & \multicolumn{2}{|c|}{$\begin{array}{l}\text { Simulation 6-10 } \\
(n=4)\end{array}$} & \multirow{2}{*}{$\begin{array}{l}p \text {-value } \\
-\end{array}$} & \multicolumn{2}{|c|}{$\begin{array}{l}\text { Simulation } 1-5 \\
(n=6)\end{array}$} & \multicolumn{2}{|c|}{$\begin{array}{l}\text { Simulation 6-10 } \\
(n=6)\end{array}$} & \multirow{2}{*}{$\begin{array}{l}p \text {-value } \\
-\end{array}$} \\
\hline & Mean & $\pm S D$ & Mean & $\pm S D$ & & Mean & $\pm S D$ & Mean & $\pm S D$ & \\
\hline $\begin{array}{l}\text { Total duration } \\
\text { (min) }\end{array}$ & 21.88 & 8.79 & 16.99 & 5.29 & $p=0.045$ & 40.00 & 16.73 & 23.92 & 6.99 & $p \leq \mathbf{0 . 0 0 1}$ \\
\hline $\begin{array}{l}\text { Fluoroscopy time } \\
\text { (min }\end{array}$ & 12.49 & 5.27 & 11.23 & 3.61 & $p=0.465$ & 22.68 & 7.98 & 14.87 & 5.10 & $p \leq \mathbf{0 . 0 0 1}$ \\
\hline $\begin{array}{l}\text { Total time of se- } \\
\text { ries } \\
(\mathrm{min})\end{array}$ & 1.99 & 0.84 & 1.79 & 0.76 & $p=0.588$ & 1.84 & 0.79 & 1.67 & 0.80 & $p=0.492$ \\
\hline \multirow{2}{*}{$\begin{array}{l}\text { Contrast agent } \\
(\mathrm{ml})\end{array}$} & 54.05 & 22.41 & 49.62 & 20.20 & $p=0.423$ & 75.82 & 34.14 & 58.58 & 24.75 & $p=0.045$ \\
\hline & Median & $I Q R$ & Median & $I Q R$ & - & Median & $I Q R$ & Median & $I Q R$ & - \\
\hline Number of series & 17 & 9 & 16 & 12 & $p=0.978$ & 17 & 6 & 16 & 11 & $p=0.439$ \\
\hline $\begin{array}{l}\text { Number of mate- } \\
\text { rial changes }\end{array}$ & 1 & 1 & 1 & 2 & $p=0.839$ & 2 & 2 & 1.5 & 1 & $p=0.267$ \\
\hline $\begin{array}{l}\text { NASA-TLX } \\
\text { (range 1-20): }\end{array}$ & Median & $I Q R$ & Median & $I Q R$ & - & Median & $I Q R$ & Median & $I Q R$ & - \\
\hline Mental demand & 10 & 9 & 10 & 8 & $p=0.762$ & 11.5 & 9 & 10 & 6 & $p=0.439$ \\
\hline Physical demand & 4 & 4 & 5 & 6 & $p=0.762$ & 4 & 2 & 5.5 & 5 & $p=0.434$ \\
\hline Temporal demand & 8 & 8 & 7 & 7 & $p=0.762$ & 6.5 & 7 & 6 & 5 & $p=1.000$ \\
\hline $\begin{array}{l}\text { Satisfaction with } \\
\text { performance }\end{array}$ & 17 & 2 & 16 & 4 & $p=0.226$ & 13.5 & 6 & 16 & 2 & $p=0.009$ \\
\hline Effort & 11.5 & 7 & 11 & 6 & $p=0.978$ & 15.5 & 3 & 13.5 & 5 & $p=0.796$ \\
\hline Frustration & 5.5 & 5 & 7 & 3 & $p=0.392$ & 5 & 7 & 4 & 5 & $p=0.595$ \\
\hline $\begin{array}{l}\text { Physiological } \\
\text { data: }\end{array}$ & Mean & $\pm S D$ & Mean & $\pm S D$ & - & Mean & $\pm S D$ & Mean & $\pm S D$ & - \\
\hline Heart rate (bpm) & 78.06 & 7.74 & 80.14 & 10.25 & $p=0.220$ & 84.07 & 14.88 & 78.86 & 12.47 & $p=0.322$ \\
\hline $\begin{array}{l}\text { Viewing direction } \\
(\%)^{\mathrm{a}}\end{array}$ & 27.47 & 12.00 & 31.68 & 16.69 & $p=0.377$ & 31.55 & 18.31 & 28.60 & 9.70 & $p=0.982$ \\
\hline
\end{tabular}

Median and IQR for number of series, number of material changes and results of NASA-TLX, $p$-values of mediantest $<0.05$ are in bold type. Mean for total duration, fluoroscopy time, total time of series and amount of contrast agent, heart rate and gaze direction, $p$-values of Mann Whitney-U-Test $<0.05$ are in bold type

aPercentage of deviation of more than $30^{\circ}$ from the horizontal view downwards.

tion with performance [median] 15.5 (IQR 5) to 16 (IQR 3), $p=0.022$ ).

Again, these differences remained significant only for beginners (Table 3). Neither heart rate, nor viewing direction differed in experts or beginners between known and unknown cases.

\section{Discussion}

In this study it was possible to prove the construct validity of a neuroangiographic simulator by demonstrating significant performance differences between beginners and experts. We were furthermore able to show the effectiveness of such a simulator by directly measuring significant improvements in psychomotor skills of beginners in cases derived from real patient anatomy.
This is in line with previous studies on different scenarios, such as carotid artery stenting $[13,18]$ and several infra-aortic applications [9, 17] and addresses one major concern regarding neuroangiographic simulations: In 2008, Carroll and Messenger stated that "medical simulation has made the transition from an experimental technology to the clinical world", and that "perhaps the most pressing issue [...] regarding medical simulation is validation" [27].

To prove the construct validity, we had clearly separated groups of beginners with a maximum of 30 cerebral angiographies performed and of experts with at least 100 procedures. The simulator data for all 10 procedures evidently demonstrated this subdivision. As previously confirmed for cardiac angiography [28], beginners need more time to find and examine the target vessels. Thus, total duration and fluoroscopy time differed significantly. Beginners more often produced roadmaps; accordingly, the total amount of contrast agent was significantly higher for beginners. The fact 


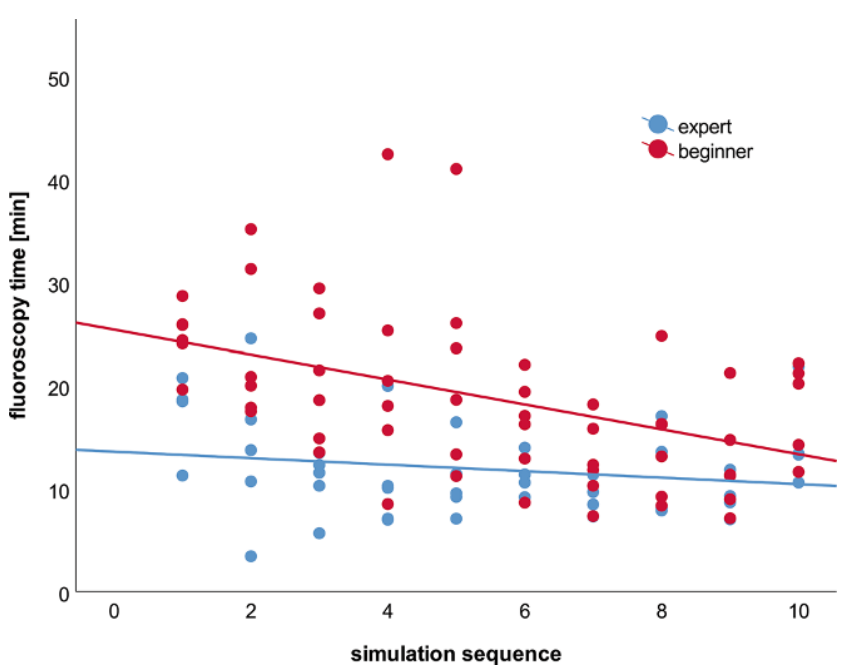

Fig. 2 Fluoroscopy time of beginners (red) and experts (blue) with corresponding regression line during all 10 simulations. Cases 1,4 and 5 are repeated (in same order) in cases 6,9 and 10 respectively that the simulator only shows the contrast of the arteries and contains no parenchyma or the venous phase may serve as a reason for the missing difference in the duration of the series. Thus, in this parameter no difference was present between experts and beginners. Overall, these results contradict the findings of Nguyen et al. who were only able to identify the amount of contrast agent as a distinguishing feature for the experience level [20]. A possible reason could be their small number of 2 compared tasks, while our study design consisted of 10 procedures.

Observations of gaze direction, blink frequency, pupil size and dwell time are recognized means of examining attention and cognitive stress [29]. Based on such data Richstone et al. were able to distinguish unequivocally between beginners and experts in surgical laparoscopy [30], but for endovascular cardiac interventions, Currie et al. found hardly any differences [31]. The assumption that experts would turn their gaze less often away from the X-ray screen could therefore not be confirmed by them. The present study focused on the direction of each sub-

Table 3 Comparison of experts and beginners regarding unknown and known cases

\begin{tabular}{|c|c|c|c|c|c|c|c|c|c|c|}
\hline \multirow[b]{3}{*}{ Simulation data: } & \multicolumn{5}{|c|}{ Experts $(n=4)$} & \multicolumn{5}{|c|}{ Beginners $(n=6)$} \\
\hline & \multicolumn{2}{|l|}{$\begin{array}{l}\text { Unknown } \\
\text { cases }\end{array}$} & \multicolumn{2}{|c|}{ Known cases } & \multirow{2}{*}{$\begin{array}{l}p \text {-value } \\
-\end{array}$} & \multicolumn{2}{|l|}{$\begin{array}{l}\text { Unknown } \\
\text { cases }\end{array}$} & \multicolumn{2}{|c|}{ Known cases } & \multirow{2}{*}{$\begin{array}{l}p \text {-value } \\
-\end{array}$} \\
\hline & Mean & $\pm S D$ & Mean & $\pm S D$ & & Mean & $\pm S D$ & Mean & $\pm S D$ & \\
\hline $\begin{array}{l}\text { Total duration } \\
\text { (min }\end{array}$ & 20.90 & 8.42 & 16.34 & 4.19 & $p=0.131$ & 35.91 & 16.03 & 22.73 & 6.37 & $p \leq 0.001$ \\
\hline $\begin{array}{l}\text { Fluoroscopy time } \\
\text { (min) }\end{array}$ & 12.36 & 5.03 & 10.71 & 2.98 & $p=0.397$ & 20.66 & 7.90 & 14.39 & 5.19 & $p=0.003$ \\
\hline $\begin{array}{l}\text { Total time of } \\
\text { series (min) }\end{array}$ & 1.93 & 0.83 & 1.83 & 074 & $p=0.765$ & 1.81 & 0.78 & 1.64 & 0.82 & $p=0.529$ \\
\hline \multirow{2}{*}{$\begin{array}{l}\text { Contrast agent } \\
(\mathrm{ml})\end{array}$} & 52.84 & 22.04 & 49.89 & 19.98 & $p=0.745$ & 71.95 & 30.90 & 56.12 & 28.43 & $p=0.058$ \\
\hline & Median & $I Q R$ & Median & $I Q R$ & - & Median & $I Q R$ & Median & $I Q R$ & - \\
\hline Number of series & 17 & 12 & 16 & 7 & $p=0.878$ & 17 & 7 & 16 & 11 & $p=0.398$ \\
\hline $\begin{array}{l}\text { Number of material } \\
\text { changes }\end{array}$ & 1 & 1 & 1 & 2 & $p=0.673$ & 2 & 2 & 1 & 1 & $p=0.183$ \\
\hline $\begin{array}{l}N A S A-T L X \\
\text { (range 1-20): }\end{array}$ & Median & $I Q R$ & Median & $I Q R$ & - & Median & $I Q R$ & Median & $I Q R$ & - \\
\hline Mental demand & 10 & 9 & 8 & 8 & $p=0.735$ & 11.5 & 9 & 8 & 6 & $p=0.398$ \\
\hline Physical demand & 4 & 4 & 5 & 6 & $p=0.735$ & 5 & 4 & 5 & 4 & $p=0.865$ \\
\hline Temporal demand & 8 & 7 & 7 & 7 & $p=0.735$ & 6.5 & 7 & 6 & 5 & $p=0.910$ \\
\hline $\begin{array}{l}\text { Satisfaction with perfor- } \\
\text { mance }\end{array}$ & 17 & 3 & 15.5 & 4 & $p=0.338$ & 14 & 6 & 16 & 2 & $p=0.022$ \\
\hline Effort & 12.5 & 5 & 9.5 & 6 & $p=0.406$ & 15.5 & 3 & 13 & 7 & $p=0.611$ \\
\hline Frustration & 6 & 5 & 6.5 & 2 & $p=0.975$ & 5 & 8 & 4 & 3 & $p=0.164$ \\
\hline Physiological data: & Mean & $\pm S D$ & Mean & $\pm S D$ & - & Mean & $\pm S D$ & Mean & $\pm S D$ & - \\
\hline Heart rate (bpm) & 78.77 & 8.41 & 79.61 & 10.54 & $p=0.524$ & 82.4 & 14.30 & 79.09 & 12.85 & $p=0.594$ \\
\hline Viewing direction $(\%)^{\mathrm{a}}$ & 27.75 & 13.36 & 33.73 & 16.38 & $p=0.234$ & 30.79 & 16.43 & 28.41 & 9.23 & $p=0.949$ \\
\hline
\end{tabular}

Median and IQR for number of series, number of material changes and results of NASA-TLX, $p$-values of median test $<0.05$ are in bold type. Mean for total duration, fluoroscopy time, total time of series and amount of contrast agent, heart rate and gaze direction, $p$-values of Mann Whitney U-test $<0.05$ are in bold type

aPercentage of deviation of more than $30^{\circ}$ from the horizontal view downwards 
ject's gaze; no differences between the two groups could be observed.

Heart rate was recorded, as it was assumed that it would differ between various levels of workload and thus between beginners and experts according to the effort made. In previous work on anesthesiologists, Martin et al. as well as Weinger et al. found significant differences in several heart rate parameters, including mean heart rate, during different phases of an anesthetic procedure [32, 42]. In a later work of the first group on pre-hospital emergency medicine, heart rate variability discriminated better between different levels of workload compared to the mean heart rate [33]. Currie et al. also measured numerous parameters such as heart rate variability, electrodermal activity and skin temperature in physicians undertaking cardiac endovascular procedures but could not find differences between experience levels [31]. Hence, mean heart rate seems to be an unreliable predictor, matching the results of our study, where it was not suitable to distinguish between beginners and experts.

The NASA-TLX is a frequently used tool to assess subjective workload, especially in anesthesia and the field of emergency care [34], but also in other areas, e.g. radiotherapy [35] or flight simulation [36]. In comparison with the previously mentioned complex technical tools, the NASATLX offers an easy and fast method for recording the workload. The modified version Raw-TLX (RTLX), without the weighting process of the subscales, is even easier to use [37]. In a study on surgical robotics, differences were found in NASA RTLX by examiners with different experience levels [38], just as in our participants. Apparently, there are no data on whether NASA RTLX changes differently through training of beginners compared to experts. The satisfaction of our participants only increased when the other measurable parameters also improved, which was only true for beginners. We therefore assume that the simulator is well suitable to give adequate feedback on one's own performance.

An increase in performance with respect to the two essential parameters of total duration and fluoroscopy time has been demonstrated in our study for beginners and confirmed the results of Spiotta et al. and Zaika et al. [10, 24]. Among our participants, however, this effect could not be observed among experts. Thus, not every experience level benefits from simulator training that focuses exclusively on diagnostic angiography. This supports the assumption that in the best case skills are learned that an expert already possesses. For beginners, the training effect can be objectively read from the metrics of the simulator, as known for peripheral endovascular procedures [14, 39]. In addition, we have shown that repeated exercises of the same cases are helpful for beginners not only to increase their metric values, but also to increase their own satisfaction. Spiotta et al. also noted an increase in confidence in the acquisition of skills, both in terms of knowledge of the anatomy and the technique of vessel selection [23]. Not least for this reason, several centers have now begun to implement a structured milestone-based curriculum and propose to integrate simulation training into formal neuroendovascular training [23, 40]

When demonstrating a training effect, it is always difficult to distinguish the extent to which a real gain in specific psychomotor skills overlaps with increasing familiarity with the operation of the simulator [39]. An improvement merely by habituation would be recognizable in all subjects; however, since only the group of beginners improved their performance relevantly, this effect seems to be negligible here.

Notably, in the RTLX evaluation, the degree of frustration of the experts slightly increased during training, whereas it decreased among the beginners (both not significant). Comments from the participants showed that individual experts were disturbed by the differences between simulation and reality, whereas beginners were not. The participants of a simulator training should therefore be informed in advance with respect to the differences that can be expected in the behavior of the simulator in relation to reality. Otherwise, they approach the training with a variety of ideas and demands, and frustration and anger can easily arise [1].

\section{Limitations}

Construct validity should distinguish not only between beginners and experts, but ideally also between various levels of experience [16]. In our study, the small number of test persons prevented further division of study participants. Also, the number of cases, in particular of repeated cases was limited in this study. A higher number of cases might also show differences in expert neuroradiologists.

\section{Conclusion}

Construct validity of a high-tech simulator could be demonstrated for diagnostic neuroangiography and especially beginners showed a measurable training effect through repeated practice. Further studies should demonstrate the benefit of such simulation training for the patient.

Funding Open Access funding provided by Projekt DEAL.

\section{Compliance with ethical guidelines}

Conflict of interest K. Kreiser conducts research in areas of interest similar to the business interests of Mentice AB (Gothenburg, Sweden). 
She gets minor travel grants, but no personal fees. She consults for phenox and has received speaker fees from Philips, Penumbra and Stryker. The Department of Neuroradiology has received research support and investigator fees for clinical studies from Biogen Idec, Quintiles, MSD Sharp \& Dome, Boehringer Ingelheim, Inventive Health Clinical UK Ltd., Advance Cor, Brainsgate, Pfizer, Bayer-Schering, Novartis, Roche, Servier, Penumbra, WCT GmbH, Syngis, SSS International Clinical Research, PPD Germany GmbH, Worldwide Clinical Trials Ltd., Phenox, Covidien, Actelion, Medivation, Medtronic, Harrison Clinical Research, Concentric, Pharmtrace, Reverse Medical Corp., Premier Research Germany Ltd., Surpass Medical Ltd., GlaxoSmithKline, AXON Neuroscience, Bristol-Myers Squibb, Genentech, Acandis, EISAI, NeuroRx, Italfarmaco, Bioclinica, MIAC and IXICO. No patents issued and pending. C. Zimmer disclosed no relevant relationships regarding activities related to the present article. He has served on scientific advisory boards for Philips and Bayer Schering; serves as coeditor on the Advisory Board of Clinical Neuroradiology; has received speaker fees from Bayer-Schering and Philips. J.S. Kirschke received speaker fees from Philips. L. Ströber, K.G. Gehling, F. Schneider, S. Kohlbecher and C.M. Schulz declare that they have no competing interests.

Ethical standards The study has been approved by the local ethics committee (172/14). All procedures performed in studies involving human participants or on human tissue were in accordance with the ethical standards of the institutional and/or national research committee and with the 1975 Helsinki declaration and its later amendments or comparable ethical standards. Informed consent was obtained from all individual participants included in the study. The manuscript does not contain clinical studies.

Open Access This article is licensed under a Creative Commons Attribution 4.0 International License, which permits use, sharing, adaptation, distribution and reproduction in any medium or format, as long as you give appropriate credit to the original author(s) and the source, provide a link to the Creative Commons licence, and indicate if changes were made. The images or other third party material in this article are included in the article's Creative Commons licence, unless indicated otherwise in a credit line to the material. If material is not included in the article's Creative Commons licence and your intended use is not permitted by statutory regulation or exceeds the permitted use, you will need to obtain permission directly from the copyright holder. To view a copy of this licence, visit http://creativecommons.org/licenses/by/4. $0 /$.

\section{References}

1. Berlis A, Morhard D, Weber W. On the basis of the DeGIR/DGNR register nationwide care for acute ischemic stroke patients in 2016 and 2017 using mechanical thrombectomy by radiologists and neuroradiologists. Rofo. 2019;191:613-7.

2. Saver JL, Goyal M, Bonafe A, Diener HC, Levy EI, Pereira VM, et al. Stent-retriever thrombectomy after intravenous t-PA vs. t-PA alone in stroke. N Engl J Med. 2015;372:2285-95.

3. Jovin TG, Chamorro A, Cobo E, de Miquel MA, Molina CA, Rovira A, et al. Thrombectomy within 8 hours after symptom onset in ischemic stroke. N Engl J Med. 2015;372:2296-306.

4. Goyal M, Demchuk AM, Menon BK, Eesa M, Rempel JL, Thornton J, et al. Randomized assessment of rapid endovascular treatment of ischemic stroke. N Engl J Med. 2015;372:1019-30.

5. Berkhemer OA, Fransen PS, Beumer D, van den Berg LA, Lingsma $\mathrm{HF}$, Yoo AJ, et al. A randomized trial of intraarterial treatment for acute ischemic stroke. N Engl J Med. 2015;372:11-20.
6. Campbell BC, Mitchell PJ, Kleinig TJ, Dewey HM, Churilov L, Yassi N, et al. Endovascular therapy for ischemic stroke with perfusion-imaging selection. N Engl J Med. 2015;372:1009-18.

7. Nogueira RG, Jadhav AP, Haussen DC, Bonafe A, Budzik RF, Bhuva $P$, et al. Thrombectomy 6 to 24 hours after stroke with a mismatch between deficit and infarct. N Engl J Med. 2018;378:11-21.

8. Albers GW, Marks MP, Kemp S, Christensen S, Tsai JP, OrtegaGutierrez S, et al. Thrombectomy for stroke at 6 to 16 hours with selection by perfusion imaging. N Engl J Med. 2018;378:708-18.

9. Schimmel DR, Sweis R, Cohen ER, Davidson C, Wayne DB. Targeting clinical outcomes: Endovascular simulation improves diagnostic coronary angiography skills. Catheter Cardiovasc Interv. 2016;87:383-8.

10. Spiotta AM, Rasmussen PA, Masaryk TJ, Benzel EC, Schlenk R. Simulated diagnostic cerebral angiography in neurosurgical training: a pilot program. J Neurointerv Surg. 2013;5:376-81.

11. Chui CK, Li Z, Anderson JH, Murphy K, Venbrux A, Ma X, et al. Training and pretreatment planning of interventional neuroradiology procedures-initial clinical validation. Stud Health Technol Inform. 2002;85:96-102.

12. Wu X, Pegoraro V, Luboz V, Neumann PF, Bardsley R, Dawson S, et al. New approaches to computer-based interventional neuroradiology training. Stud Health Technol Inform. 2005;111:602-7.

13. Nicholson WJ, Cates CU, Patel AD, Niazi K, Palmer S, Helmy T, et al. Face and content validation of virtual reality simulation for carotid angiography: results from the first 100 physicians attending the Emory NeuroAnatomy Carotid Training (ENACT) program. Simul Healthc. 2006;1:147-50.

14. Coates PJ, Zealley IA, Chakraverty S. Endovascular simulator is of benefit in the acquisition of basic skills by novice operators. J Vasc Interv Radiol. 2010;21:130-4.

15. Aggarwal R, Black SA, Hance JR, Darzi A, Cheshire NJ. Virtual reality simulation training can improve inexperienced surgeons' endovascular skills. Eur J Vasc Endovasc Surg. 2006;31:588-93.

16. Jensen UJ, Jensen J, Olivecrona GK, Ahlberg G, Tornvall P. Technical skills assessment in a coronary angiography simulator for construct validation. Simul Healthc. 2013;8:324-8.

17. Lipner RS, Messenger JC, Kangilaski R, Baim DS, Holmes DR Jr, Williams DO, et al. A technical and cognitive skills evaluation of performance in interventional cardiology procedures using medical simulation. Simul Healthc. 2010;5:65-74.

18. Berry M, Reznick R, Lystig T, Lonn L. The use of virtual reality for training in carotid artery stenting: a construct validation study. Acta Radiol. 2008;49:801-5.

19. Van Herzeele I, Aggarwal R, Choong A, Brightwell R, Vermassen FE, Cheshire NJ. Virtual reality simulation objectively differentiates level of carotid stent experience in experienced interventionalists. J Vasc Surg. 2007;46:855-63.

20. Nguyen N, Eagleson R, Boulton M, de Ribaupierre S. Realism, criterion validity, and training capability of simulated diagnostic cerebral angiography. Stud Health Technol Inform. 2014;196:297-303.

21. Ahmed K, Keeling AN, Fakhry M, Ashrafian H, Aggarwal R, Naughton PA, Darzi A, Cheshire N, Athanasiou T, Hamady M. Role of virtual reality simulation in teaching and assessing technical skills in endovascular intervention. J Vasc Interv Radiol. 2010;21:55-66.

22. Liebig T, Holtmannspötter M, Crossley R, Lindkvist J, Henn P, Lönn L, et al. Metric-based virtual reality simulation: a paradigm shift in training for mechanical thrombectomy in acute stroke. Stroke. 2018;49:e239-42.

23. Spiotta AM, Kellogg RT, Vargas J, Chaudry MI, Turk AS, Turner RD. Diagnostic angiography skill acquisition with a secondary curve catheter: phase 2 of a curriculum-based endovascular simulation program. J Neurointerv Surg. 2015;7:777-80.

24. Zaika O, Nguyen N, Boulton M, Eagleson R, de Ribaupierre S. Evaluation of user performance in simulation-based diagnos- 
tic cerebral angiography training. Stud Health Technol Inform. 2016;220:465-8.

25. Kaufmann T, Sütterlin S, Schulz SM, Vögele C. ARTiiFACT: a tool for heart rate artifact processing and heart rate variability analysis. Behav Res Methods. 2011;43:1161-70.

26. Hart SG, Staveland LE. Development of NASA-TLX (Task Load Index): results of empirical and theoretical research. Adv Psychol. 1988;52:139-83.

27. Carroll JD, Messenger JC. Medical simulation: the new tool for training and skill assessment. Perspect Biol Med. 2008;51:47-60.

28. Jensen UJ, Lagerquist B, Jensen J, Tornvall P. The use of fluoroscopy to construct learning curves for coronary angiography. Catheter Cardiovasc Interv. 2012;80:564-9.

29. Marshall SP. The Index of Cognitive Activity: measuring cognitive workload. Proceedings of the IEEE 7th Conference on Human Factors and Power Plants, Scottsdale, AZ, USA, 2002, pp. 7-7.

30. Richstone L, Schwartz MJ, Seideman C, Cadeddu J, Marshall S, Kavoussi LR. Eye metrics as an objective assessment of surgical skill. Ann Surg. 2010;252:177-82.

31. Currie J, Bond RR, McCullagh P, Black P, Finlay DD, Gallagher $\mathrm{S}$, et al. Wearable technology-based metrics for predicting operator performance during cardiac catheterisation. Int J Comput Assist Radiol Surg. 2019;14:645-57.

32. Martin J, Schneider F, Kowalewskij A, Jordan D, Hapfelmeier A, Kochs EF, et al. Linear and non-linear heart rate metrics for the assessment of anaesthetists' workload during general anaesthesia. Br J Anaesth. 2016;117:767-74.

33. Weinger MB, Reddy SB, Slagle JM. Multiple measures of anesthesia workload during teaching and nonteaching cases. Anesth Analg. 2004;98:1419-25.

34. Schneider F, Martin J, Hapfelmeier A, Jordan D, Schneider G, Schulz CM. The validity of linear and non-linear heart rate met- rics as workload indicators of emergency physicians. PLoS One. 2017;12:e188635.

35. Schneider F, Martin J, Schneider G, Schulz CM. The impact of the patient's initial NACA score on subjective and physiological indicators of workload during pre-hospital emergency care. Plos One. 2018;13:e202215.

36. Mazur LM, Mosaly PR, Jackson M, Chang SX, Burkhardt KD, Adams RD, et al. Quantitative assessment of workload and stressors in clinical radiation oncology. Int J Radiat Oncol Biol Phys. 2012;83:e571-6.

37. Mansikka H, Virtanen K, Harris D. Comparison of NASATLX scale, modified cooper-harper scale and mean inter-beat interval as measures of pilot mental workload during simulated flight tasks. Ergonomics. 2019;62:246-54.

38. Hart SG. Nasa-Task Load Index (NASA-TLX); 20 Years Later. Proceedings of the Human Factors and Ergonomics Society Annual Meeting, 2006;50:904-8.

39. Dulan G, Rege RV, Hogg DC, Gilberg-Fisher KM, Arain NA, Tesfay ST, Scott DJ. Proficiency-based training for robotic surgery: construct validity, workload, and expert levels for nin inanimate exercises. Surg Endosc. 2012;26:1516-21.

40. Glaiberman CB, Jacobs B, Street M, Duncan JR, Scerbo MW, Pilgrim TK. Simulation in training: one-year experience using an efficiency index to assess interventional radiology fellow training status. J Vasc Interv Radiol. 2008;19:1366e71.

41. Kreiser K, Gehling K, Zimmer C. Simulation in angiography-experiences from 5 years teaching, training, and research. Rofo. 2019;191:547-52.

42. Dieckmann P, Wehner T. Über Grundsätze zur Gestaltung von Simulatorsettings für Forschung und Lehre. Harburger Beiträge zur Psychologie und Soziologie der Arbeit, Vol. 31. 2002. 